\title{
DAMPAK GENDER, SOURCING CHANNELS, AND PLACEMENT TERHADAP KINERJA KARYAWAN
}

\author{
Mutmainah ${ }^{1}$ \\ Taufik Dian Murseto ${ }^{2}$ \\ Ahadiati Rohmatiah ${ }^{3}$ \\ Universitas Merdeka Madiun, Jawa Timur, Indonesia ${ }^{1,2,3}$ \\ Email: mutmainah@unmer-madiun.ac.id ${ }^{1}$ \\ taufikdianmurseto97@gmail.com ${ }^{2}$ \\ ahadiati@unmer-madiun.ac.id ${ }^{3}$
}

\begin{abstract}
This research purpose to know of affect gender, sourching channels, and placement on employee performance PT BPR Ekadharma Bhinaraharja. The number of respondens were 69 employee of PT BPR Ekadharma Bhinaraharja in Kawedanan Magetan. Sampling technique use sensus sampling. Analysis method in this research use multiple regression analysis with SmartPLS programme. The results show gender not affect on employee performance, Sourcing Channels affect on employee performance, and placement affect on employee performance. This research model is 59,9 percent, as much 40,5 percent formed by others variable.
\end{abstract}

Keywords: Gender; Sourcing Channels; Placement; Employee Performance

\begin{abstract}
ABSTRAK
Penelitian ini bertujuan untuk mengetahui pengaruh gender, Sourcing Channels, dan placement terhadap kinerja karyawan PT BPR Ekadharma Bhinaraharja. Jumlah responden sebanyak 69 karyawan PT BPR Ekadharma Bhinaraharja di Kawedanan Magetan. Teknik pengambilan sampel dilakukan secara jenuh. Metode analisis yang digunakan menggunakan analisis regresi linier berganda dengan bantuan program SmartPLS. Hasil penelitian menunjukkan gender tidak berpengaruh terhadap kinerja karyawan, Sourcing Channels berpengaruh terhadap kinerja karyawan, dan placement berpengaruh terhadap kinerja karyawan. Model yang terbentuk dari penelitian ini yaitu sebesar 59,5\%, sisanya sebesar $40,5 \%$ dibentuk oleh variabel-variabel yang lain.
\end{abstract}

Kata kunci: Gender; Sourcing Channels; Placement; Kinerja Karyawan 


\section{PENDAHULUAN}

Karyawan merupakan human capital bagi perusahaan. Kinerjanya dapat menentukan perkembangan sebuah perusahaan. Sehingga didalam menentukan calon karyawan harus sesuai dengan kriteria kualifikasi jabatan yang dituju. Kinerja atau prestasi kerja merupakan suatu keberhasilan individu dalam mengerjakan tugasnya (Ratnasari \& Hartati, 2019). Seberapa besar keberhasilan karyawan dalam menjalankan tugasnya akan berdampak pada keberlanjutan perusahaan. Sehingga dalam mendapatkan karyawan haruslah tepat. Mendapatkan karyawan yang sesuai dengan kualifikasi tidak lepas dari strategi menentukan gender yang sesuai dengan jabatan yang dituju. Seperti hasil penelitian Kotur \& Anbazhagan (2014) menunjukkan bahwa gender dapat mempengaruhi kinerja karyawan. Karyawan laki-laki dan perempuan mempunyai level kinerja yang berbeda. Hasil penelitian tersebut juga menyebutkan karyawan perempuan lebih produktif daripada karyawan laki-laki. Senada dengan penelitian tersebut, penelitian Wilda, dkk (2020) mengungkapkan bahwa gender laki-laki dan perempuan mempunyai kemampuan yang berbeda dalam menyelesaikan pekerjaan yang dianggap berat. Hal ini menunjukkan bahwa terdapat aspek pekerjaan tertentu yang menghasilkan kinerja karyawan perempuan lebih unggul, seperti pekerjaan yang berhubungan dengan pelayanan pelanggan. Penelitian Dhani \& Sharma (2017) menunjukkan terdapat hubungan yang signifikan antara gender dengan kinerja dan kecerdasan emosional (emotional intelligence) karyawan. Karyawan perempuan dapat menghasilkan kinerja yang lebih baik daripada karyawan laki-laki. Tapi kecerdasan emosional karyawan laki-laki lebih tinggi daripada karyawan perempuan. Sehingga 
posisi pengambil kebijakan lebih baik laki-laki daripada perempuan.

Hasil yang berbeda ditunjukkan oleh penelitian Ogunleye \& Osekita (2016) \& Mutmainah (2014), gender tidak berpengaruh terhadap kinerja karyawan. Hasil penelitian tersebut dimungkinkan disebabkan adanya stereotype dan prestis dari budaya yang ada di wilayah tersebut. Menurut Robbins \& Judge (2008), tidak terdapat perbedaan yang signifikan antara laki-laki dan perempuan dalam hal kemampuan, memecahkan masalah, menganalisa, dorongan kompetitif, motivasi, sosiabilitas, atau kemampuan belajar. Berbagai penelitian psikologis menunjukkan bahwa laki-laki lebih mungkin dapat diharapkan untuk sukses daripada perempuan. Akan tetapi, tidak terdapat perbedaan signifikan antara laki-laki dan perempuan mengenai produktivitas kerja. Perbedaan-perbedaan hasil penelitian ini masih menjadi perdebatan diantara peneliti sampai sekarang. Oleh sebab itu, tidak sedikit yang tertarik untuk membahas lebih mendalam mengenai gender dan kinerja ini. Keterkaitan antara gender dengan kinerja ini dapat mungkin terjadi pada PT BPR Ekadharma Bhinaraharja Kawedanan Magetan, mengingat jumlah karyawan lakilaki lebih sedikit dibandingkan dengan perempuan.

Strategi yang lain dalam mendapatkan karyawan yang sesuai kualifikasi adalah penentuan saluran rekrutmen (Sourcing Channels). Saluran rekrutmen (Sourcing Channels) merupakan cara-cara yang dapat digunakan perusahaan untuk mendapatkan karyawan yang sesuai dengan kualifikasi yang diinginkan. Proses rekrutmen akan efektif jika dalam menentukan saluran rekrutmen sesuai dengan sasaran yang dituju (kualifikasi). Ketepatan penentuan strategi ini juga akan menentukan banyak sedikitnya calon karyawan yang akan melamar. Sourcing 
Channels terdiri dari job posting, skill inventory, referrals, walks-in, writes-in, melalui perguruan tinggi, lembaga pelatihan dan pendidikan, open house, iklan, agen penempatan tenaga kerja, konsultan, dan leasing. Dalam prakteknya dapat menggunakan lebih dari satu Sourcing Channels. Penggunaan Sourcing Channels ini tergantung dari tujuan perusahaan. PT BPR Ekadharma Bhinaraharja Kawedanan Magetan selama ini hanya menggunakan Sourcing Channels jenis referrals dan iklan. Jenis Sourcing Channels ini dinilai efektif dalam mendapatkan karyawan baru dalam waktu singkat tapi belum dapat menjamin kinerja karyawan yang dihasilkan. Hal ini mengindikasikan bahwa PT BPR Ekadharma Bhinaraharja Kawedanan Magetan mengabaikan kinerja calon karyawan ke depannya karena Sourcing Channels yang dipilih terbatas. Semakin banyak Sourcing Channels yang dipilih, maka kesempatan mendapatkan karyawan yang sesuai kualifikasi akan semakin besar dan kesempatan mendapatkan kinerja yang berkualitas juga akan semakin tinggi. Keterkaitan antara Sourcing Channels dengan kinerja karyawan didukung hasil penelitian Agus (2019) yang menunjukkan bahwa rekrutmen berpengaruh terhadap kinerja karyawan. Berbeda dari hasil penelitian Suwarto \& Subyantoro (2019) yang menunjukkan bahwa rekrutmen tidak berpengaruh terhadap kinerja karyawan. Penyebabnya, kemungkinan dikarenakan jalur hubungan yang tidak secara langsung (melalui perantara).

Keberhasilan dalam mendapatkan karyawan yang sesuai dengan kualifikasi tidak hanya pada saluran rekrutmen (Sourcing Channels) dan gender, tapi menempatkan karyawan sesuai dengan kemampuannya (placement) juga tidak kalah penting. Menurut Gaol (2014), placement (penempatan pegawai) adalah suatu 
pengaturan awal atau pengaturan kembali dari seorang atau lebih pegawai pada suatu jabatan baru ataupun jabatan yang berlainan. Menurut Agustina, dkk (2019), jika proses placement ini tidak dilakukan secara tepat akan mempengaruhi pencapaian tujuan organisasi. Berdasarkan Sarinah, dkk (2016) menyatakan bahwa placement yang tepat merupakan motivasi yang dapat meningkatkan moralitas dan antusias tinggi seseorang dalam menghasilkan kinerja. Umumnya, proses placement dilakukan dan diputuskan oleh atasan langsung. Tentunya, melalui konsultasi dari Human Resource Management kepada atasan langsung dari calon karyawan tersebut. Ini dilakukan dengan tujuan mengetahui apakah kemampuan calon karyawan sesuai dengan posisi (jabatan) yang dilamar. Proses placement harus dilakukan secara tepat agar perusahaan tidak kehilangan pelanggan.

Ketika sebuah perusahaan dalam menentukan kualifikasi yang diinginkan, menentukan Sourcing Channels dan placement yang tepat, maka perusahaan akan mendapatkan karyawan yang sesuai dengan visi dan misi perusahaan. Hal ini akan dapat mengembangkan perusahaan dengan cepat dan keberlangsungan hidup perusahaan juga akan terjamin. Selain itu, ketepatan karyawan yang diperoleh juga akan berdampak pada kehidupan para karyawan. Sehingga ini dapat dikatakan kondisi simbiosis mutualisme. Hasil penelitian Agus (2019); Sudiardhita, dkk (2019); Suwarto \& Subyantoro (2019) menunjukkan terdapat pengaruh positif antara penempatan (placement) dengan kinerja karyawan. Sehingga penelitian ini juga ingin mengetahui pengaruh placement terhadap kinerja karyawan, mengingat Sourcing Channels yang diterapkan hanya melalui referrals dan iklan. 


\section{METODE PENELITIAN}

Teknik pengambilan sampel pada penelitian kuantitatif ini adalah sensus, yaitu jumlah populasi keseluruhan dijadikan sampel, berjumlah 69 karyawan. Penelitian dilakukan di PT BPR Ekadharma Bhinaraharja Kawedanan Kabupaten Magetan. Jenis dan sumber data yang diambil berupa data sekunder (buku referensi, jurnal, profil perusahaan) dan data primer berupa angket. Variabel independen dalam penelitian ini adalah Gender (X1), Sourcing Channels (X2), dan Placement (X3). Sedangkan variabel dependennya adalah Kinerja karyawan (Y). Gender (X1) menggunakan skala nominal dengan pilihan jawaban terdiri dari laki-laki (disimbolkan dengan angka 1) dan perempuan (disimbolkan dengan angka 2). Sourcing Channels (X2) menurut Handoko (2011) adalah metode-metode dalam penarikan karyawan. Sourcing Channels (X2) dengan indikator terdiri dari referrals (terdiri dari 1 pernyataan $(\mathrm{X} 2.1)$ ) dan job posting (terdiri dari 1 pernyataan (X2.2)). Placement (X3) menurut Gaol (2014), penempatan kerja merupakan penempatan awal pada suatu jabatan atau posisi bagi pegawai baru. Placement (X3) dengan indikator terdiri dari kesesuaian dengan pendidikan (terdiri dari 1 pernyataan (X3.1)), pengetahuan kerja (terdiri dari 1 pernyataan (X3.2)), keterampilan kerja (terdiri dari 1 pernyataan (X3.3)), dan pengalaman kerja (terdiri dari 1 pernyataan (X3.3)). Kinerja (Y) dapat diukur menggunakan indikator yang terdiri dari Mathis \& Jackson (2009) kualitas kerja (terdiri dari 2 pernyataan yaitu Y.1 dan Y.2), ketepatan waktu (terdiri dari 2 pernyataan yaitu Y.3 dan Y.4), kehadiran (terdiri dari 2 pernyataan yaitu Y.5 dan Y.6), dan kemampuan (terdiri dari 2 pernyataan yaitu Y.7 dan Y.8). Pilihan respon angket untuk variabel X2, X3, dan Y 
menggunakan skala 1-5 dimulai dari sangat tidak setuju (1), tidak setuju (2), cukup setuju (3), setuju (4), dan sangat setuju (5). Metode analisis data menggunakan regresi linier berganda dengan program SmartPLS dikarenakan jumlah responden kurang dari 100. Sehingga untuk menguji kevalidan instrument menggunakan convergent validity (terdiri dari Loading Factor dan Average Variance Extracted $(A V E)$ ) dan discriminant validity (terdiri dari Fornell Larckel Criterion or HTMT dan Cross Loading), sedangkan untuk menguji reliabilitas menggunakan Composite Reliability dan Cronbach's Alpha.

H1 : Gender (X1) berpengaruh terhadap kinerja karyawan (Y)

H2 : Sourcing Channels (X2) berpengaruh terhadap kinerja karyawan (Y)

H3 : Placement (X3) berpengaruh terhadap kinerja karyawan (Y)

\section{HASIL DAN PEMBAHASAN}

Berdasarkan hasil penelitian, didapat jumlah karyawan perempuan dan karyawan laki-laki pada PT BPR Ekadharma Bhinaraharja Kawedanan Magetan disajikan dalam Tabel 1.

Tabel 1.

Karakteristik Responden Berdasarkan Jenis Kelamin

\begin{tabular}{lcc}
\hline Jenis Kelamin & Jumlah (orang) & Prosentase (\%) \\
\hline Laki-laki & 29 & $42 \%$ \\
Perempuan & 40 & $58 \%$ \\
\hline Total & $\mathbf{6 9}$ & $\mathbf{1 0 0 \%}$
\end{tabular}

Sumber: Data primer diolah, 2020

Berdasarkan Tabel 1, sebagian besar pegawai PT BPR Ekadharma Bhinaraharja Kawedanan Magetan berjenis kelamin perempuan (58\%), kurang dari 
separuhnya berjenis kelamin laki-laki (42\%). Hal ini menunjukkan bahwa karyawan PT BPR Ekadharma Bhinaraharja Kawedanan Magetan didominasi oleh karyawan yang berjenis kelamin perempuan.

Pengujian instrument dilakukan dengan uji validitas dan reliabilitas. Terdapat item pernyataan Y.4, Y.5, dan Y.6 yang tidak valid karena nilai Loading Factor kurang dari 0,70. Tampilan hasil SmartPLS seperti pada Tabel 2.

Tabel 2.

Hasil Uji Validitas Pertama dengan Loading Factor

\begin{tabular}{ccccc}
\hline \multirow{2}{*}{$\begin{array}{c}\text { Item } \\
\text { pernyataan }\end{array}$} & \multicolumn{4}{c}{ Variabel } \\
\cline { 3 - 5 } & $\begin{array}{c}\text { X1 } \\
\text { Gender }\end{array}$ & $\begin{array}{c}\text { X2 } \\
\text { Sourcing } \\
\text { Channels }\end{array}$ & $\begin{array}{c}\text { X3 } \\
\text { Placement }\end{array}$ & $\begin{array}{c}\text { Y } \\
\text { Kinerja }\end{array}$ \\
X1 & 1.000 & & & \\
X2.1 & & 0.908 & & \\
X2.2 & & 0.879 & & \\
X3.1 & & & 0.810 & \\
X3.2 & & 0.868 & \\
X3.3 & & 0.898 & \\
X3.4 & & 0.806 & \\
Y.1 & & & 0.726 \\
Y.2 & & & 0.725 \\
Y.3 & & & 0.709 \\
Y.4 & & & $\mathbf{0 . 5 0 0}$ \\
Y.5 & & & $\mathbf{0 . 6 1 0}$ \\
Y.6 & & & $\mathbf{0 . 6 9 9}$ \\
Y.7 & & & 0.836 \\
Y.8 & & & 0.790 \\
\hline Sumber: Data primer diolah, 2020 & &
\end{tabular}

Item pernyataan yang tidak valid (dalam Tabel 2 diberi warna merah) dihapus dari model. Maka model analisis regresi berganda berbentuk seperti Gambar 1 dan hasil uji validitas kedua dengan Loading Factor dapat dilihat pada Tabel 3. 


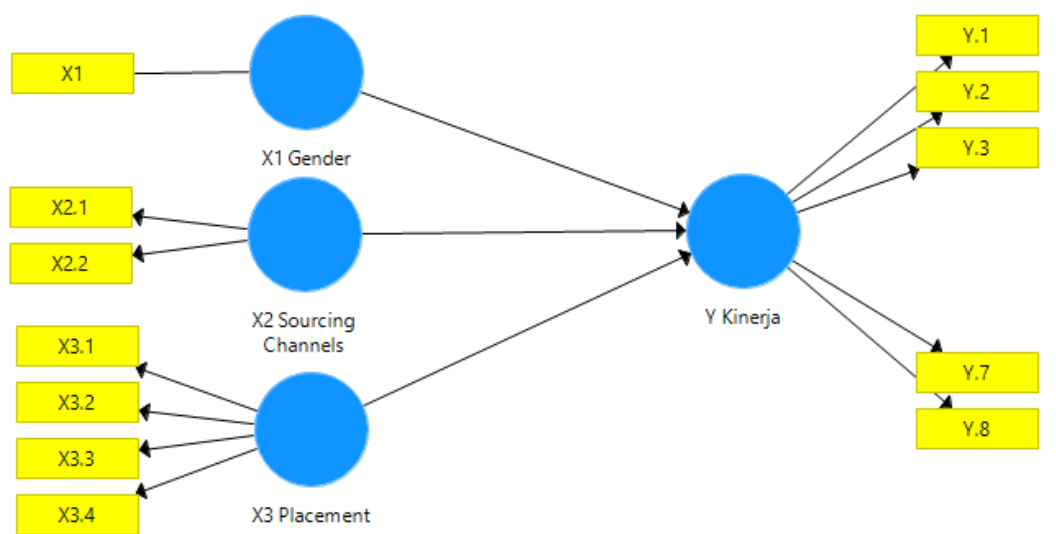

Sumber: Data primer diolah, 2020

Gambar 1.

Model Regresi Berganda Setelah Mengeluarkan Y.4, Y.5, Y.6

Berikut resum hasil uji validitas dan reliabilitas disajikan dalam Tabel 3.

Tabel 3.

Resum Hasil Uji Validitas Instrumen

\begin{tabular}{|c|c|c|c|c|}
\hline \multirow{3}{*}{ Variabel } & \multirow{3}{*}{ Indikator } & \multicolumn{2}{|c|}{ Convergent Validity } & Discriminant Validity \\
\hline & & $\begin{array}{l}\text { Loading } \\
\text { Factor } \\
(>0,70)\end{array}$ & AVE & \multirow[t]{2}{*}{ Fornell Larcker Criterion (Valid) } \\
\hline & & $\begin{array}{l}\text { Cross } \\
\text { Loading }\end{array}$ & $(>\mathbf{0 , 5})$ & \\
\hline \multirow{3}{*}{$\begin{array}{l}\text { Gender } \\
\text { (X1) } \\
\text { Sourcing } \\
\text { Channels } \\
\text { (X2) }\end{array}$} & $\mathrm{X} 1$ & 1,000 & 1,000 & \multirow{12}{*}{$\begin{array}{l}\text { X1 --> X1 (1.000) } \\
\text { X2 --> X2 }(0.894)>\text { X2 --> X1 } \\
(0.211) \\
\text { X3 --> X3 }(0.846)>\text { X3 --> X1 } \\
(0.071), X 3->\text { X2 (0.308) } \\
\text { Y --> Y }(0.786)>\text { Y --> X1 (0.033), } \\
\text { Y --> X2 (0.350), Y --> X3 (0.616) }\end{array}$} \\
\hline & $\mathrm{X} 2.1$ & 0,902 & & \\
\hline & $\mathrm{X} 2.2$ & 0,886 & 0,799 & \\
\hline \multirow{4}{*}{$\begin{array}{l}\text { Placement } \\
\text { (X3) }\end{array}$} & $\mathrm{X} 3.1$ & 0,813 & \multirow{4}{*}{0,715} & \\
\hline & $\mathrm{X} 3.2$ & 0,858 & & \\
\hline & $\mathrm{X} 3.3$ & 0,895 & & \\
\hline & $\mathrm{X} 3.4$ & 0,814 & & \\
\hline \multirow{5}{*}{$\begin{array}{l}\text { Kinerja } \\
(\mathrm{Y})\end{array}$} & $\mathrm{Y} 1$ & 0,816 & \multirow{5}{*}{0,618} & \\
\hline & $\mathrm{Y} 2$ & 0,802 & & \\
\hline & $\mathrm{Y} 3$ & 0,749 & & \\
\hline & $\mathrm{Y} 7$ & 0,799 & & \\
\hline & Y8 & 0,762 & & \\
\hline
\end{tabular}


Berdasarkan Tabel 3, instrument penelitian telah memenuhi validitas instrument. Berikut hasil uji reliabilitas disajikan dalam Tabel 4.

Tabel 4.

Resum Hasil Uji Reliabilitas

\begin{tabular}{ccccc}
\hline Variabel & $\begin{array}{c}\text { Cronbach's } \\
\text { Alpha }\end{array}$ & Keterangan & $\begin{array}{c}\text { Composite } \\
\text { Reliability }\end{array}$ & Keterangan \\
\hline X1 & 1.000 & Reliabel & 1.000 & Reliabel \\
X2 & 0.749 & Reliabel & 0.888 & Reliabel \\
X3 & 0.867 & Reliabel & 0.909 & Reliabel \\
Y & 0.845 & Reliabel & 0.890 & Reliabel \\
\hline
\end{tabular}

Sumber: Output SmartPLS, 2020

Berdasarkan Tabel 4, variable X1 (Gender), X2 (Sourcing Channels), X3 (Placement), dan Y (Kinerja karyawan) dinyatakan reliabel. Instrumen penelitian dan variabel penelitian telah valid dan reliabel, sehingga proses statistik dapat dilanjutkan ke proses analisa berikutnya.

Model Fit yang terbentuk dalam model regresi ini sebesar 0,595 atau 59,5\% (nilai NFI). Hal ini menunjukkan bahwa model regresi yang terbentuk sebesar 59,5 \%. Hal ini berarti model variabel Gender, Sourcing Channels, dan Placement dalam mempengaruhi Kinerja karyawan sebesar 59,5\%, sisanya sebesar 40,5\% dipengaruhi oleh variabel lain yang belum masuk dalam model regresi ini. Variabel lain yang ada kaitannya dengan kinerja karyawan seperti yang disebutkan Shaleh (2018) adalah komitmen organisasi dan budaya organisasi.

Untuk melakukan uji hipotesis, dapat dilakukan dengan melihat nilai TStatistik (t hitung) pada uji bootstrapping. Nilai T-Statistik ini akan dibandingkan dengan t tabel. $\mathrm{T}$ tabel dapat diperoleh $\mathrm{n}-1=69-1=68$, dengan $\mathrm{n}$ adalah jumlah sampel, dan alpha 5\%. Sehingga diperoleh t tabel 1,66757. Berikut hasil olah 
SmartPLS uji T-Statistik disajikan dalam Tabel 5.

Tabel 5.

Resume hasil SmartPLS T-Statistics

\begin{tabular}{cccc}
\hline Hubungan & $\begin{array}{c}\text { Nilai t hitung (T- } \\
\text { Statistics) }\end{array}$ & T tabel & Keterangan \\
\hline $\mathrm{X} 1 \rightarrow \mathrm{Y}$ & 0,642 & 1,66757 & Tidak signifikan/tidak \\
& & & berpengaruh \\
$\mathrm{X} 2 \rightarrow \mathrm{Y}$ & 1,968 & 1,66757 & Signifikan/Berpengaruh \\
$\mathrm{X} 3 \rightarrow \mathrm{Y}$ & 8,463 & 1,66757 & Signifikan/Berpengaruh \\
\hline
\end{tabular}

Sumber: Data primer diolah, 2020

Berdasarkan Tabel 5, hasil SmartPLS tersebut dapat diinterpretasikan sebagai berikut:

Hasil penelitian menunjukkan Gender (X1) tidak berpengaruh terhadap kinerja karyawan (Y) PT BPR Ekadharma Bhinaraharja Kawedanan Magetan. Hal ini sesuai dengan teori Robbins \& Judge (2008) yang menyatakan bahwa tidak ada perbedaan signifikan antara laki-laki dan perempuan berkaitan dengan produktivitas. Selain itu, didukung pula oleh hasil penelitian Ogunleye \& Osekita (2016); Mutmainah (2014).

Seringkali karyawan yang berjenis kelamin laki-laki dikaitkan dengan pekerjaan yang membutuhkan tenaga fisik. Karyawan yang bekerja di bank seperti karyawan PT BPR Ekadharma Bhinaraharja Kawedanan Magetan merupakan karyawan yang jenis pekerjaannya tidak membutuhkan tenaga fisik sepenuhnya dalam menyelesaikan tugasnya tapi membutuhkan kecerdasan emosional, intelektual, dan daya pikir. Disamping itu, divisi yang jenis pekerjaannya membutuhkan tenaga fisik seperti sales dan debt collector, yang kadang kala harus berkunjung ke rumah nasabah, di-handle oleh karyawan yang berjenis kelamin laki- 
laki. Tenaga fisik laki-laki secara psikologi dianggap lebih kuat daripada perempuan. Sehingga posisi sales dan debt collector lebih sesuai diberikan kepada karyawan yang berjenis kelamin laki-laki. Hal ini bertujuan mencegah terjadi halhal yang tidak diinginkan saat menjalankan tugasnya di luar tempat kerja, seperti pelecehan seksual, tindak kriminal, dan lain sebagainya. Perusahaan juga tidak menutup kemungkinan jika posisi sales atau debt collector dibebankan kepada karyawan perempuan. Kemampuan dalam berhasil menawarkan produk perusahaan, berhasil mendapatkan pembayaran angsuran nasabah, dan lain sebagainya merupakan salah satu tolak ukur dalam menghasilkan kinerja yang baik. Oleh sebab itu, pada PT BPR Ekadharma Bhinaraharja Kawedanan Magetan Gender karyawan tidak menentukan hasil kerja karyawan.

Hasil penelitian menunjukkan bahwa Sourcing Channels (X2) berpengaruh terhadap kinerja karyawan (Y) PT BPR Ekadharma Bhinaraharja Kawedanan Magetan. Hasil penelitian ini berbeda dengan hasil penelitian Agus (2019) dan Suwarto \& Subyantoro (2019) yang menemukan bahwa rekrutmen tidak berpengaruh terhadap kinerja, dimana indikator rekrutmen terdiri dari internal dan eksternal (indikator sama dengan penelitian ini).

Sourcing Channels (X2) melalui iklan dan referrals dianggap efektif bagi PT BPR Ekadharma Bhinaraharja Kawedanan Magetan dalam mendapatkan karyawan baru yang kompeten. Selain itu, Sourcing Channels tersebut tidak memerlukan biaya yang besar dalam menerapkannya dan lebih cepat dalam mendapatkan karyawan baru. Semakin baik pemilihan Sourcing Channels untuk mendapatkan karyawan baru bagi perusahaan, maka akan semakin efektif dalam 
mendapatkan kandidat. Tentu saja dalam pemilihan Sourcing Channels tidak mengabaikan kualifikasi yang telah ditentukan perusahaan. Seperti Sourcing Channels melalui referrals, perusahaan menginformasikan kepada karyawan PT BPR Ekadharma Bhinaraharja Kawedanan Magetan jika ada lowongan pekerjaan di perusahaan tersebut. Sehingga para karyawan dapat menginformasikan kepada orang-orang yang dikenalnya. Kelebihan cara ini adalah perusahaan dapat mengetahui detail tentang kemampuan dan kepribadian kandidat tersebut dari karyawannya sendiri. Jika tidak sesuai dengan kriteria, karyawan tersebut tidak akan merekomendasikan ke perusahaan. Sehingga hal ini dapat mengefisiensi tenaga dan waktu untuk tes wawancara. Selain itu, rekomendasi dari karyawan dapat merebut karyawan lain yang potensial dari tempat kerjanya. Kemudian pindah bekerja di PT BPR Ekadharma Bhinaraharja Kawedanan Magetan. Akan tetapi, referrals ini juga mempunyai kelemahan. Menurut Simamora (2006), saluran ini memicu diskriminasi dan nepotisme, serta menimbulkan kekecewaan terhadap karyawan jika orang yang direkomendasikan ditolak. Hal ini dapat menimbulkan hubungan yang kurang baik antara karyawan dengan perusahaan, baik karyawan yang merekomendasikan maupun karyawan yang lain. Sehingga dapat dimungkinkan akan berdampak pada kinerja karyawan. Akan tetapi, pada PT BPR Ekadharma Bhinaraharja Kawedanan Magetan hal ini tidak terjadi. Disebabkan karyawan yang lain akan merasa lebih senang jika posisi yang lowong segera terisi oleh karyawan baik karyawan baru maupun lama. Karena beban kerja mereka tidak bertambah, tidak menumpuk, dan selesai dengan tepat waktu. 
Sourcing Channels melalui iklan menjadi strategi kedua PT BPR Ekadharma Bhinaraharja Kawedanan Magetan dalam melakukan penarikan karyawan. Sourcing Channels ini dipilih disebabkan perusahaan ingin mendapatkan calon karyawan yang memenuhi kualifikasi secara lebih meluas. Walaupun Sourcing Channels ini sedikit membutuhkan waktu lebih panjang daripada referrals, tapi perusahaan selama ini mendapatkannya sesuai dengan harapan. Kedua saluran ini selama ini berhasil diterapkan, terbukti dengan hasil kerja karyawan PT BPR Ekadharma Bhinaraharja Kawedanan Magetan yang memuaskan, artinya karyawan dapat menyelesaikan pekerjaannya sesuai dengan waktu yang telah ditentukan (standar perusahaan). Selain itu, PT BPR Ekadharma Bhinaraharja Kawedanan Magetan selama ini belum pernah mendapatkan komplain dari nasabah mengenai pelayanan yang diberikan.

Yang perlu diperhatikan oleh PT BPR Ekadharma Bhinaraharja Kawedanan Magetan, selain menentukan Sourcing Channels yang tepat dalam mendapatkan kandidat karyawan, menurut Simamora (2006) perusahaan juga perlu untuk mengetahui pekerjaan apa saja atau jenis pekerjaan yang bagaimana yang sedang lowong. Serta mengidentifikasi kualifikasi karyawan yang akan mendudukinya. Hal ini bertujuan agar dalam melakukan perekrutan secara efektif dan efisien dan mendapatkan karyawan yang perusahaan inginkan.

Hasil penelitian menunjukkan bahwa Placement (X3) berpengaruh terhadap kinerja karyawan (Y) PT BPR Ekadharma Bhinaraharja Kawedanan Magetan. Hasil ini didukung oleh Agus (2019); Suwarto \& Subyantoro (2019); Sudiardhita dkk., (2019). Penempatan posisi karyawan yang tepat akan berdampak pada hasil 
kerjanya. Seperti posisi sales dan debt collector pada PT BPR Ekadharma Bhinaraharja Kawedanan Magetan ditempati oleh karyawan yang berjenis kelamin laki-laki. Salah satu alasannya adalah untuk menghindari hal-hal yang tidak diinginkan pada saat menjalankan tugas, seperti tindak kriminal, pelecehan seksual, dan lain sebagainya. Selain itu, karyawan laki-laki cenderung lebih menyukai pekerjaan di luar ruangan dibandingkan dengan karyawan perempuan. Kesesuaian kemampuan dengan pekerjaan juga turut berperan dalam meningkatkan kinerja karyawan. Seperti karyawan yang mampu menyelesaikan pekerjaan sesuai dengan waktu yang ditargetkan perusahaan. Kualifikasi ini harus dimiliki oleh karyawan PT BPR Ekadharma Bhinaraharja Kawedanan Magetan karena berkaitan dengan pelayanan nasabah. Pelayanan yang diberikan kepada nasabah haruslah yang terbaik agar perusahaan tidak kehilangan nasabah (pindah ke lembaga keuangan yang lain).

Penempatan karyawan yang dilakukan secara prinsip "The right man on the right place" akan menghasilkan kinerja yang optimal. Adanya penempatan (placememt) ini adalah mengarahkan perilaku, HRD menempatkan seorang karyawan atau calon karyawan pada posisi tertentu agar lebih produktif dalam melaksanakan pekerjaan yang dibebankan, serta untuk meningkatkan kemampuan dan keterampilan sebagai dasar kelancaran melaksanakan tugas (Arifin, 2019). Artinya bahwa karyawan akan lebih bersemangat dalam bekerja disebabkan bidang yang digelutinya merupakan sesuatu hal yang dikuasai dengan baik atau sesuai dengan kemampuan, keahlian, dan kompetensi. Kesesuaian ini juga dapat berdampak kinerja perusahaan menjadi lebih baik. 


\section{SIMPULAN DAN SARAN}

Dari hasil penelitian menunjukkan bahwa Gender (X1) tidak berpengaruh terhadap kinerja karyawan (Y) PT BPR Ekadharma Bhinaraharja Kawedanan Magetan. Yang membedakan dari kedua jenis kelamin ini adalah tenaga fisik ketika menempati posisi atau jabatan yang membutuhkan tenaga besar atau kuat untuk perlindungan diri. Seperti posisi sales dan debt collector. Laki-laki dianggap mempunyai tenaga yang lebih besar dibandingkan perempuan. Sehingga ketika karyawan laki-laki menghadapi tindak kriminal seperti pelecehan seksual, perampokan, dan lain sebagainya, dapat melakukan perlawanan. Sedangkan perempuan dianggap tenaganya tidak sebesar atau tidak sekuat laki-laki. Sehingga hal ini tidak mempengaruhi dari kualitas, ketepatan waktu, kehadiran, dan kemampuan karyawan dalam melaksanakan tugasnya. Variabel yang berpengaruh terhadap kinerja karyawan (Y) PT BPR Ekadharma Bhinaraharja Kawedanan Magetan adalah Sourcing Channels (X2) dan Placement (X3). Pemilihan Sourcing Channels (X2) melalui iklan akan membuka kesempatan yang besar kepada calon karyawan untuk melamar. Melibatkan karyawan dalam proses rekrutmen melalui referrals dapat mengefisiensi waktu dan biaya. Hasil kandidat yang didapat juga sesuai dengan kriteria perusahaan. Sehingga kinerja yang dihasilkan sesuai yang ditargetkan oleh perusahaan. Penempatan karyawan (Placement) (X3) yang tepat seperti mampu untuk menyelesaikan pekerjaan yang diembannya sesuai dengan batas waktu yang telah ditentukan perusahaan merupakan faktor yang penting dalam mempengaruhi kinerja karyawan. 
Hasil penelitian menunjukkan variabel gender tidak berpengaruh terhadap kinerja karyawan. PT BPR Ekadharma Bhinaraharja Kawedanan Magetan dapat merekrut karyawan untuk posisi sales dan debt collector dengan jenis kelamin perempuan. Agar perusahaan tidak khawatir dengan keselamatan karyawan di bagian tersebut, perusahaan dapat menambahkan persyaratan dengan kemampuan bela diri atau karate atau taekwondo. Atau perusahaan juga dapat mengkhususkan wilayah tertentu. Sehingga rekrutmen karyawan untuk posisi sales dan debt collector dapat menjangkau khalayak lebih luas (tidak hanya berjenis kelamin lakilaki). Pemilihan Sourcing Channels memang tergantung dari tujuan perusahaan dalam memilih saluran rekrutmen tersebut. Seperti PT BPR Ekadharma Bhinaraharja Kawedanan Magetan dalam merekrut karyawan lebih memilih iklan dan referrals. Dengan memilih iklan, perusahaan dapat menjangkau calon karyawan lebih luas dan kesempatan untuk mendapatkan kandidat yang sesuai dengan kualifikasi lebih banyak. Akan tetapi, mendapatkan kandidat lebih cepat itu lebih baik karena dapat segera untuk menyelesaikan pekerjaan yang sempat tertunda. Sehingga saluran referrals adalah pilihan yang tepat yang telah dilakukan perusahaan. Kinerja karyawan memuaskan atau tidak juga tergantung dari placement yang tepat. Kemampuan karyawan dalam menyelesaikan tugas seperti penginputan data yang harus selesai tepat waktu merupakan bentuk dari placement yang tepat yang telah dilakukan PT BPR Ekadharma Bhinaraharja Kawedanan Magetan. Disamping itu, kinerja karyawan PT BPR Ekadharma Bhinaraharja Kawedanan Magetan memuaskan atau tidak, tidak hanya dilihat dari gender, 
Sourcing Channels, dan placement, perlu dilakukan penelitian lebih lanjut mengenai kinerja karyawan. Penelitian ini masih terdapat keterbatasan. Sehingga penelitian ini dapat dikembangkan oleh peneliti yang akan datang dengan; 1) memperbesar jumlah sampel, jika jumlah sampel ditambah atau lebih banyak daripada penelitian sekarang dimungkinkan dapat memperbesar keyakinan atau kevalidan hasil penelitian. 2) Obyek penelitian di tempat berbeda atau di bidang yang berbeda, karena dimungkinkan rata-rata jawaban responden belum tentu sama sehingga dapat mempengaruhi hasil penelitian. 3) Dapat memakai metode analisis yang lain, seperti uji beda, uji ini untuk mengetahui kinerja karyawan laki-laki dan perempuan, atau dapat mencoba menggunakan metode path analysis atau PLS dengan variabel mediasi adalah Sourcing Channels. 4) Menambah variabel lain yang berkaitan dengan kinerja karyawan, karena dalam penelitian ini model yang terbentuk hanya 59,5\%, masih jauh untuk mendekati model yang hampir sempurna (mendekati angka 100\%). 5) Menambah jumlah indikator atau memakai teori yang lain jika variabel yang dipakai sama serta menambah jumlah pernyataan atau pertanyaan. Hal ini dimungkinkan tingkat validitas dan reliabilitas lebih baik.

\section{REFERENSI}

Agus, N. S. (2019). Pengaruh Rekrutmen Dan Penempatan Terhadap Kinerja Pegawai Pada kantor Pelayanan Perbendaharaan Negara (KPPN) Pematangsiantar. MAKER (Jurnal STIE Sultan Agung, 5(1), 77-88.

Agustina, Dalimunthe, R. F., \& Sinulingga, S. (2019). The Effect Of Recruitment, Training, and Placement On The Performance Of Employees in PT Astra International, Tbk, Toyota Auto 2000 SM. Raja Medan. European Journal of Human Resource Management Studies, 3(1), 1-14.

Arifin, N. (2019). Manajemen Sumber Daya Manusia: Teori dan Kasus. Jepara: 


\section{UNISNU Press.}

Dhani, P., \& Sharma, T. (2017). Effect of Emotional Intelligence On Job Performance of IT Employees: A Gender Study. Procedia Computer Science, 122, 180-185.

Gaol, C. J. (2014). A to Z Human Capital. Jakarta: PT Gramedia Widiasarana Indonesia.

Handoko, T. H. (2011). Manajemen Personalia dan Sumber Daya Manusia. Yogyakarta: BPFE Universitas Gajah Mada.

Kotur, B. R., \& Anbazhagan, S. (2014). Influence of Age and Gender On The Performance. IOSR Journal of Business and Management (IOSR-JBM), 16 (5), 97-103.

Mathis, R. L., \& Jackson, J. H. (2009). Human Resource Management, tenth edition. Jakarta: Salemba Empat.

Mutmainah. (2014). Peran Karakteristik Individu Pada Peningkatan Kinerja Karyawan. EKOMAKS, 3(1), 70-76

Ogunleye, A. J., \& Osekita, D. A. (2016). Effeect of Job Status, Gender, and Employees' Achievement Motivation Behavior on Work Performance: A Case Study of Selected Local Government Employees in Ekiti State, Nigeria. European Scientific Journal, Edisi September, 12(26),235-248

Ratnasari, S. L., \& Hartati, Y. (2019). Manajemen Kinerja Dalam Organisasi. Batam: CV Penerbit Qiara Media.

Robbins, S. P., \& Judge, T. A. (2008). Perilaku Organisasi, Buku 1. Jakarta: Salemba Empat.

Sarinah, Gulton, R. S., \& Thabah, A. A. (2016). The Effect of Recruitment and Employee Selection on Employee Placement and Its Impacts Toward Employee Performance At PT Sriwijaya Air. Jurnal Manajemen Transportasi dan Logistik, 3(1), 101-110

Shaleh, M. (2018). Komitmen Organisasi Terhadap Kinerja pegawai. Makassar: Aksara Timur.

Simamora, H. (2006). Manajemen Sumber Daya Manusia. Yogyakarta: Bagian Penerbitan STIE YKPN.

Sudiardhita, I. K., Dianta, K., Susita, D., \& Aisyah, N. (2019). Placement, Career Development, On Employee Performance With Job Satisfaction As Intervening Variables. DLSU Business \& Economics Review, 28(3), 73-80. 
Mutmainah, Taufik Dian Murseto, dan Ahadiati Rohmatiah. Dampak Gender, Sourcing.....

Suwarto, F., \& Subyantoro, A. (2019). The Effect of Recruitment, Selection and Placement on Employee Performance. International Journal of Computer Networks and Communications Security, 7(7), 126-134.

Wilda, A. Y., Sunaryo, H., \& Wahono, B. (2020). Analisis Pengaruh Gender, Beban Kerja, dan Motivasi Kerja terhadap Kinerja Karyawan. E-Jurnal Riset Manajemen (E-JRM), 9(13), 48-61.

\section{LAMPIRAN PERNYATAAN}

\begin{tabular}{|c|c|c|c|c|c|c|}
\hline \multirow[t]{2}{*}{ No. } & \multirow[t]{2}{*}{ Pernyataan } & \multicolumn{5}{|c|}{ Pilihan Jawaban } \\
\hline & & SS & $\mathbf{S}$ & CS & TS & STS \\
\hline \multicolumn{7}{|c|}{ Sourcing Channels (X2) } \\
\hline $\mathrm{X} 2.1$ & Perekrutan diinformasikan dari iklan atau surat kabar & & & & & \\
\hline $\mathrm{X} 2.2$ & Perekrutan diinformasikan dari karyawan perusahaan & & & & & \\
\hline \multicolumn{7}{|c|}{ Placement (X3) } \\
\hline $\mathrm{X} 3.1$ & $\begin{array}{l}\text { Pekerjaan yang diberikan sesuai dengan latar belakang } \\
\text { pendidikan }\end{array}$ & & & & & \\
\hline $\mathrm{X} 3.2$ & $\begin{array}{l}\text { Setiap bagian terdapat tugas dan pekerjaan masing } \\
\text { masing yang dapat dipahami dengan jelas }\end{array}$ & & & & & \\
\hline $\mathrm{X} 3.3$ & $\begin{array}{l}\text { Pekerjaan yang diberikan sesuai dengan ketrampilan } \\
\text { karyawan }\end{array}$ & & & & & \\
\hline $\mathrm{X} 3.4$ & $\begin{array}{l}\text { Pengalaman pekerjaan dapat membantu karyawan } \\
\text { dalam pekerjaanya saat ini }\end{array}$ & & & & & \\
\hline \multicolumn{7}{|c|}{$\operatorname{Kinerja}(\mathbf{Y})$} \\
\hline Y.1 & Saya bekerja secara teliti & & & & & \\
\hline Y.2 & Saya bekerja secara rapi & & & & & \\
\hline Y.3 & Saya ke kantor selalu tepat waktu & & & & & \\
\hline Y.4 & Saya selalu tepat dalam menyelesaikan pekerjaan & & & & & \\
\hline Y.5 & Saya selalu masuk kerja dihari kerja & & & & & \\
\hline Y.6 & Saya jarang tidak masuk kerja di hari kerja & & & & & \\
\hline Y.7 & $\begin{array}{l}\text { Saya mampu kerja sama dengan rekan kerja untuk } \\
\text { menyelesaikan pekerjaan }\end{array}$ & & & & & \\
\hline Y.8 & $\begin{array}{l}\text { Saya mampu kerjasama dengan pimpinan untuk } \\
\text { menyelesaikan pekerjaan }\end{array}$ & & & & & \\
\hline
\end{tabular}

